Gut, 1986, 27, 826-828

\title{
Alternative medicine consultations and remedies in patients with the irritable bowel syndrome
}

\author{
H L SMART, J F MAYBERRY, AND M ATKINSON \\ From the University Hospital, Queen's Medical Centre, Nottingham
}

SUMMARY The use of alternative medicine was assessed by questionnaire in 96 patients with irritable bowel syndrome, 143 patients with organic upper gastrointestinal disorders and 222 patients with Crohn's disease of comparable age and sex. Significantly more patients with the irritable bowel syndrome $(16 \%)$ had consulted practitioners of alternative medicine about their condition than had patients in either of the other groups. Similarly, significantly more irritable bowel syndrome patients said they would consult an alternative medicine practitioner $(41 \%)$ if conventional treatment failed. Current usage of alternative medicine remedies was significantly greater in the irritable bowel syndrome patients $(11 \%)$ than in patients with Crohn's disease $(4 \%)$ and tended to be greater than in patients with organic upper gastrointestinal disorders $(6 \%)$. This study has shown that the use of alternative medicine is common in patients with irritable bowel syndrome and this does not appear to be explicable in terms of the nature, chronicity or refractoriness to treatment of symptoms.

The irritable bowel syndrome is a common disorder which may affect up to $15 \%$ of the population ${ }^{12}$ the majority of whom never seek medical advice. ${ }^{3}$ Even so up to half the patients attending some gastroenterology clinics may have irritable bowel syndrome. ${ }^{4}$ Many of these patients will respond to a combination of reassurance and drugs such as spasmolytics and bulking agents ${ }^{56}$ but only a small number will experience a permanent cure. Up to one quarter of patients derive no benefit from such treatment and may even deteriorate. ${ }^{78}$

In 1983 over one million people in Britain consulted practitioners of alternative (complementary) medicine ${ }^{9}$ and this represented an increase of $15 \%$ over the previous year. During 1984 a number of our patients openly said that they had consulted practitioners of alternative medicine whilst continuing with conventional medical therapy. To assess the frequency of alternative medicine consultation we made a survey of 461 patients with various gastrointestinal disorders, the results of which are reported in this paper.

\footnotetext{
Methods

PATIENTS

Ninety six unselected patients with irritable bowel

Address for correspondence: Professor M Atkinson, Department of Surgery. University Hospital, Queen's Medical Centre, Nottingham NG7 2UH.

Received for publication 17 October 1985
}

syndrome and 143 patients of similar age and sex with various organic upper gastrointestinal disorders attending a gastroenterological outpatient clinic were asked to complete a questionnaire about consultation with practitioners of alternative medicine. A further 222 patients with Crohn's disease completed a similar postal questionnaire.

Patients were considered to have irritable bowel syndrome if they complained of abdominal pain and altered bowel habit together with the symptoms described by Manning et al. ${ }^{10}$ In all patients clinical examination, sigmoidoscopy and rectal biopsy, stool culture, haematological and biochemical indices, and barium enema failed to reveal abnormalities.

The group of patients with organic upper gastrointestinal disorders consisted of 93 patients with oesophageal disease (oesophagitis, peptic stricture, and motility disorders), 28 with peptic ulceration and 22 with miscellaneous disorders (including cancer and hepatobiliary disease).

\section{QUESTIONNAIRE}

Patients completed without aid the questionnaire about consultation with practitioners of alternative medicine and the use of alternative medicine remedies for their gastrointestinal condition. Details of consultation with named types of practitioners were recorded. Specific questions were asked about the type of remedies used (yoga and meditation, herbal 
and homeopathic treatments) on a regular basis (more than three times per week) to treat the patients' condition. Patients were also asked if they would consider consulting an alternative medicine practitioner if conventional treatment failed.

\section{STATISTICAL ANALYSIS}

The ages of the patients were compared with a Student's $t$ test. Chi-square analysis was used to compare consultation rates and remedy use between the patient groups.

\section{Results}

The three patient groups were of similar age and sex structure with a female predominance (Table 1). The men in all groups were younger than the women. Significantly more patients with irritable bowel syndrome had consulted alternative medicine practitioners about their condition (16\%) than had patients in either of the other two groups (Table 2). In addition, patients with irritable bowel syndrome were significantly more likely to seek such a consultation if they felt that conventional therapy had failed. Alternative remedies were also used by significantly more patients with irritable bowel syndrome $(11 \%)$ than with Crohn's disease but not by patients with upper gastrointestinal disorders. Some patients consulted more than one type of practitioner of alternative medicine with herbalists and homeopaths being the most frequently consulted practitioners (Table 3 ). Herbal remedies were the most popular kind of alternative medicine treatment used by patients at home.

Table 1 Age and sex distribution of patients participating in the alternative medicine survey

\begin{tabular}{llll}
\hline & $\begin{array}{l}\text { Irritable bowel } \\
\text { syndrome }(n=96)\end{array}$ & $\begin{array}{l}\text { Crohn's disease } \\
(n=222)\end{array}$ & $\begin{array}{l}\text { Organic upper } \\
\text { GI disorders } \\
(n=143)\end{array}$ \\
\hline $\begin{array}{lll}\text { Women } \\
\text { Age in years (mean } \pm \mathrm{SD})\end{array}$ & $67(70 \%)$ & $137(62 \%)$ & $84(59 \%)$ \\
$\quad$ Women & $45 \cdot 3 \pm 17 \cdot 8$ & $46 \cdot 9 \pm 16 \cdot 3$ & $48 \cdot 0 \pm 17 \cdot 0$ \\
Men & $40 \cdot 4 \pm 12 \cdot 2$ & $45 \cdot 2 \pm 15 \cdot 3$ & $43 \cdot 4 \pm 13 \cdot 1$ \\
\hline
\end{tabular}

Table 2 Results of alternative medicine survey

\begin{tabular}{|c|c|c|c|c|c|}
\hline & $\begin{array}{l}\text { Organic upper GI } \\
\text { disorders }(n=143)\end{array}$ & & $\begin{array}{l}\text { Irritable bowel } \\
\text { syndrome }(n=96)\end{array}$ & & $\begin{array}{l}\text { Crohn's disease } \\
(n=222)\end{array}$ \\
\hline $\begin{array}{l}\text { Consulted an alternative } \\
\text { medicine practitioner }\end{array}$ & $3(2 \%)$ & $\mathrm{p}<0.001$ & $15(16 \%)$ & $\mathrm{p}<0.02$ & $14(6 \%)$ \\
\hline $\begin{array}{l}\text { Would consider seeking } \\
\text { alternative medicine consultation }\end{array}$ & $38(27 \%)$ & $\mathrm{p}<0.05$ & $39(41 \%)$ & $\mathrm{p}<0.001$ & $42(19 \%)$ \\
\hline $\begin{array}{l}\text { Currently using alternative } \\
\text { medicine remedies }\end{array}$ & $8(6 \%)$ & $\mathrm{p}=\mathrm{ns}$ & $11(11 \%)$ & $p<0.05$ & $9(4 \%)$ \\
\hline
\end{tabular}

Table 3 Types of consultation and treatment reported by patients participating in the alternative medicine survey

\begin{tabular}{|c|c|c|c|c|c|c|}
\hline & \multicolumn{3}{|c|}{$\begin{array}{l}\text { Consultation with } \\
\text { practitioners }\end{array}$} & \multicolumn{3}{|c|}{$\begin{array}{l}\text { Current regular use } \\
\text { of alternative remedies }\end{array}$} \\
\hline & $I B S$ & Crohns & Upper GI & $I B S$ & Crohns & Upper GI \\
\hline Homeopath & 5 & 3 & 1 & 6 & 2 & 2 \\
\hline Faith healer & 1 & 3 & 3 & 0 & 0 & 0 \\
\hline Herbalist & 5 & 8 & 1 & 5 & 5 & 6 \\
\hline Clinical ecologist & 2 & 0 & 0 & 0 & 0 & 0 \\
\hline Osteopath & 1 & 1 & 1 & 0 & 0 & 0 \\
\hline Acupuncturist & 3 & 0 & 0 & 0 & 0 & 0 \\
\hline Yoga/meditation & 0 & 0 & 0 & 4 & 2 & 7 \\
\hline
\end{tabular}




\section{Discussion}

This study has shown that the use of alternative medicine, particularly in the irritable bowel syndrome, is common in patients attending a gastroenterological clinic. Clinicians should be alert to this possibility and specific enquiry should be made about concomitant use of alternative medicine as this is of particular importance in the assessment of the results of conventional treatment and in clinical trials.

Significantly more patients with irritable bowel syndrome consult practitioners of alternative medicine than do patients with upper gastrointestinal disorders or Crohn's disease and they also are more ready to do so if they believe conventional medicine has failed them. The users of alternative medicine tend to be younger, although not significantly so, than those people who are non-users, and are often women. A similar pattern has been recorded by the Institute for Complementary Medicine."

The irritable bowel syndrome is a chronic disorder which responds poorly to orthodox treatment ${ }^{8}$ and often this type of disorder is treated by practitioners of alternative medicine. ${ }^{9}$ Chronicity and response to treatment, however, are unlikely to account solely for the propensity of irritable bowel syndrome patients to seek alternative medicine treatment as these are features of the bowel symptoms of Crohn's disease where alternative medicine consultation was significantly less frequent as it was in patients with other chronic alimentary disorders.

The greater usage of alternative medicine in patients with irritable bowel syndrome possibly results from an attention seeking attitude to their disorder. Alternative medicine practitioners often have long consultation times and adopt an holistic approach to their patients' problems which would be difficult to match in a busy gastroenterological clinic. It is of interest to note that symptomatic relief has been reported with therapies such as hypnosis in the treatment of irritable bowel syndrome. " None of our patients who had sought alternative medicine treatment, however, had consulted a hypnotist.

The value of alternative medicine in the treatment of irritable bowel syndrome has not been assessed in this survey as the number of patients responding was small. The possibility that such patients may be concomitantly using alternative medicine deserves more attention in gastroenterological clinics.

We are grateful to Drs J Rhodes, B Calcraft, and JS Morris for allowing us to survey their patients with Crohn's disease.

\section{References}

1 Thompson WG, Heaton KW. Functional bowel disorders in apparently healthy people. Gastroenterology 1980; 79: 283-8.

2 Drossman DA, Sandler RS, McKee DC, Lovitz AJ. Bowel dysfunction amongst subjects not seeking health care. Gastroenterology 1982; 83: 529-34.

3 Sandler RS, Drossman DA, Nathan HP, McKee DC. Symptom complaints and health care seeking behaviour in subjects with bowel dysfunction. Gastroenterology 1984; 87: 314-8.

4 Switz DM. What the gastroenterologist does all day. Gastroenterology 1976; 70: 1048-50.

5 Fielding JF. The irritable bowel syndrome. Clin Gastroenterol 1977; 6: 607-22.

6 Thompson WG. The irritable bowel. Gut 1984; 25: 305-20.

7 Choudhary NA, Truelove SC. The irritable colon syndrome. $Q$ J Med 1963; 31: 307-22.

8 Waller SL, Misiewicz JJ. Prognosis in the iritable bowel syndrome. Lancet 1969; 2: 753-6.

9 Davies P. Report on trends in complementary medicine. London: The Institute for Complementary Medicine, 1984.

10 Manning AP, Thompson WG, Heaton KW, Morris AF. Towards positive diagnosis of the irritable bowel. Br Med J 1978; 2: 653-4.

11 Whorwell PJ, Prior A, Faragher EB. Controlled trial of hypnotherapy in the treatment of severe refractory irritable bowel syndrome. Lancet 1984; 2: 1232-3. 